Journal of Contemporary Educational Research

Research Article

\title{
Research on the New Mode of college students' mental Health Education under the Network environment
}

Xue Han*

Harbin University of Commerce, Harbin 150028, Heilongjian Province Province, China

\begin{abstract}
With the rapid development of science and technology, internet technology has become mature increasingly. It has become an important part of people's work, life and study. At the same time, the network environment has also brought an impact on the physical and mental health of college students. Nowadays, the quality and level of college students' mental health education has become society topics. College psychological health education work should keep pace with the network environment development and the students' physical and mental development. It is the effective innovation of psychological health education work. The new model of college students' psychological health education development is constructed. It is improve the level of students' physical and mental health development, and the psychological quality of college students is strengthen. Based on this, this paper analyzes the existing problems on the college students' mental health development. Under the network environment, it proposes an effective method to construct a new mode of college students' mental health education .
\end{abstract}

Keywords: Network environment; College students; Mental health; New models of education; Explore

Publication date: August, 2020

Publication online: 31 August, 2020

*Corresponding author: Xue Han, hanxue_home@163. com

Colleges are the bases of talent training for China's economic and social development. The teaching quality is related to the talent training quality directly. College students are important successors to the China's socialist construction and development. Therefore, the healthy physical and mental development of college students has been widely concerned by all society. With the rapid development and improvement of Internet technology, college students' life style, learning style and interpersonal relationship are also affected by the network environment. It has a great changes. According to the data of students' physical and mental health, it shows that the current of the college students' physical and mental health situation is grim. The number of the psychological disorders and heart diseases is increasing. The college students' physical and mental are affected. We should change the traditional mode because of the passive situation and the psychological quality. Based on the background, the construction studies of a new mode of mental health education for college students in the network environment is analyzed. It analyzes the existing problems on the current mental health development of college students. The proposes is to construct a new mode of mental health education for college students in the network environment.

\section{Problems existing in the mental health development of contemporary college students under the network development environment}

Network is the era development theme of Internet technology. The rapid development promotes the rapid development of economy and society. There have differences between realistic environment and network environment, such as the characteristics of virtual sex, openness and so on. contemporary college students' psychological development also has a certain influence, The paper discusses the problem on mental health development of contemporary college studentsthrough the following aspects 


\subsection{Analysis of existing problems in the field of interpersonal communication}

In the Internet information age, changes have taken place in the college students' interpersonal environment, communication platform and the interpersonal communication way. College students communicate with strangers through these social networking platform, such as WeChat, weibo, QQ and network software. On the one hand, college studentscan tell oneself with strangers in the real environment encountered in some problems.And also vent some long delay in the heart of dissatisfaction and unhappinessto a stranger. Someone can tell some truth, even unscrupulous and arbitrary to a stranger[1]. Over time, someone indulges in this way inadvertently. They are killing the efforts which I should have made in the real world.It is ignoring some self-adjustment and self-reflection whice I should have made. Most students feel fresh about the Internet at first, or try to relieve the pressure in real study and life temporarily by chatting on the Internet.They get temporary comfort or pleasure. The key is habit-forming network, the "lotus"network modecan offset at the feeling, such as analgesic drugs. When leaving a virtual network space, all problems will still be in real life. Most of the students will choose to escape and forget reality through the network cheerful and relaxed herself when face the real life need to solve the problem. Over time, the loss of the courage and ability to solve the problem[2].The personality construction collapse.The overall development of college students and personality development caused a heavy blow. On the other hand, college students can also share some happiness with strangers on the Internet. They record their happiness, sorrow and happiness through the cyberspace. They imprint their life every day. All the pleasure of slowly flowing in the heartthroughsharing, recording and speaking.There is no longer rely for risingcyberspace. The vanity and novel feeling are responsed through the network expansiontype and different message from strangers. It multiples perspectives, obtains the growth experiencebenefits and gives the needle "drug" for students. It makes the students excited about different stories and interesting, and forget that distinguish various view of value and purpose ${ }^{[3]}$. It is possible to lose in taste the sense of integrity and justice. They tend to have some ulterior motive for thinking their unique. It has a serious negative impact on the values of college students. Worryingly, it goes on and along with the interest qinling into the heart of college students unconsciously. It is too late to correct one by one. Mental health has been damaged seriously but do not know. Mental health has been damagebadly, but also didn't know it.Psychological education workers may not be able to detect them. Therefore,mental health educators should have a clear understanding and countermeasures to the threats and invasions implied in the network. They should lay a foundation for the mental health education of the college students. In addition, many college students will be on the network environment for a long time.There will be a phenomenon of life from the real life and learning, not only lack of communication with parents, classmates, and rarely participate in collective activities organized by the school.There Will be divorced from the real environment, lose the courage and ability to face the reality. It is resulting in interpersonal communication obstacles.

\subsection{Analysis of existing problems in cognitive ability}

College students' cognition and personality become matureincreasingly.They should have a clear position on their own learning. But under the network environment, the students whose self-control ability is not strong have cognitive interference because of the multiple values and the network information. It is difficult to define the difference between reality and the network environment. It causes students to fall into theirselves predicament. At the same time, in the network environment, there are some phenomena of money worship and hedonism that affect the right values of college students ${ }^{[4]}$. If students have insufficient cognition of these phenomena, they will show recognition and convergence attitude. It will affect students' life planning and even cause the subversion of their outlook on life, values and world outlook. Based on this, if college students can't get healthy education and guidance, it will lead them to the wrong life path.

\section{Analysis of effective strategies for constructing a new mode of mental health education for college students under the network environment}

\subsection{Strengthen the construction of psychological consultation rooms in universities and improve the network psychological consultation system}

First, during the construction of psychological consultation room in colleges and universities, we should take into account the healthy development of both body and mind of all college students. The object of consultation should be classified in detail. If the counseling objects can be divided into students who 
expect psychological help, students with mental health problems who want health guidance, students with mental health problems who do not know themselves, and students with good mental health and need developmental guidance.

Second, after identifying the target of guidance, We should also strengthen the construction of mental health professional teachers. In particular, mental health professional teachers should be strengthened on the potential problems in the network environment. Even the inevitable problems and possible problems have presupposition understanding and cognition ${ }^{[5]}$. According to the students' language, description, as well as the process of communication habits, state and other aspects of performance. It makes a more accurate judgment on the students' psychological condition. It is able to understand the root that causes the students' psychological problems. It helps students to understand their own psychological problems effectively. Encourage students to receive psychological counseling and medical treatment actively. In addition, psychological education professional teachers should have the quality of caring love. They should avoid facing questions with strange, surprised eyes or gestures. The effective development of psychological education counseling work makes students feel warm and safe beginning. The college students' mental health education will be put into practice so as to complete the mental health education and guidance in a relaxed atmosphere.

The third, The construction of psychological education consultation room should also pay attention to the introduction of advanced instruments. It should pay attention to build diversity, richness, fun combination of psychological education guidance testing system. It enhance the attractiveness of psychological tests and counselling through diversity, richness and interest. It win the trust and affection of the college students ${ }^{[6]}$. In order to carry on the sampling analysis to its psychological state naturally. tries hard to complete the psychological test in the relaxed and happy. It try to complete the psychological test with ease and pleasure. In addition, the convenience network should be used to improve the psychological counseling system. It creates immediate, effective and diverse psychological counseling methods and related systems both online and offline. On the one hand, college students are accustomed and loved Internet browsing and communication generally. We can "heal a man in his own way." For example, it can enrich the ways and methods of psychological counseling through online appointment time, online fun psychological tests, the construction of the communication space and platform between teachers and students in the online psychological education consultation. On the other hand, the construction and layout of the offline psychological consultation room should also have a warm, caring, relaxed and relieved style and function. It creates a sense of psychological comfort and comfort for his students. A duty system shall be established in the psychological consultation room. A system for answering questions will be established immediately, and make sure students ask questions. There must be a teacher to give answers. And in the confidentiality aspect, the privacy aspect completes the corresponding work. According to the situation of students, male and female psychological counseling teachers are arranged. It provides the basic guarantee for students to have smooth and clear communication. In addition, online consultation education and offline consultation education should be combined organically. Online consultation is a rich avenue of methods as a means of supporting offline work. However, guiding students to do face-to-face offline counseling is the main body and goal of psychological counseling education ${ }^{[7]}$. It draws students' attention. It enriched and filled the effectiveness of offline work. It plays an important role in helping students with their mental health.

\subsection{Strengthen specialized training for mental health educators}

The network environment has symbolic, virtual, spatiotemporal characteristics. Therefore, it also requires higher professional ability of mental health educators. On the one hand, mental health educators should have the mental health basic theory ${ }^{[8]}$. It enhances and enriches the cognition depth and the application ability to the mental health theory continuously. It strengthens its own cognition of mental health education theory through specialized training. It should keep pace with the times and use them flexibly. On the other hand, mental health educators should have the ability to use computer network technology to carry out mental health education skillfully. We should improve our knowledge of the Internet constantly, and improve the ability to use network technology at the same time improve $^{[9]}$. In the process of learning computer network technology, it has a deep understanding of the nature and potential problems of computers and networks. It lays a foundation for carrying out vivid and effective psychological education.

In summary, college students are the builders and successors of China's socialist. In a network environment, the physical and mental development of students is affected. In order to promote mental health 
education with the times, mental health education in colleges and universities can only build new models constantly ${ }^{[10]}$. It promotes the improvement of students' psychological quality and the comprehensive quality ability.

Acknowledgments: This work was supported by the 2020 School Ideological and Political Work Research Project. Applied Research on Improving the College Students' IdeologicalEffectivenessand Political Education from the Perspective of Group Dynamics.

\section{References}

[1] Niu DL. Research on the New Mode of College Students' Mental Health Education under the Network Environment[J]. Media Forum, 2019(11).

[2] Zhou C, Wang Lu. Construction on a New Mode of Mental health Education for College Students in the Network Environment[J]. Knowledge Economy, 2018(08).

[3] Lei X. Analysis and Reflection on the Embedded Mode of Financial and Economic literacy Education in Guangxi Universities -- A Case Study of College Students' Mental Health Education[J]. Think Tank Era, 2018(24).
[4] Zhang Z. A Brief introduction on the new Mode of college students' Mental health education[A]. Proceedings of The Chinese Society for Educational Development Strategies[C].2019(4).

[5] Zhao W. Analysis of college students' mental health education in the network era[J]. Psychology monthly, 2020, 15(13): 27.

[6] Luo YS, Yang Z, Yang X, et al. Cultural psychological characteristics of online games, positive and negative thoughts on personality growth of college students[J]. Industry and Technology Forum, 2020, 19(09): 110-111.

[7] Jiang J, Tang M, Wang DY, et al. Literature review of college students' online consumption and its psychology research -analysis based on CNKI data knowledge map[J]. Journal of Jiangsu Second Normal University, 2020, 36(02): 54-59.

[8] Cui GH. Model Construction of College Students' Mental Health Education in the InternetEra --OnNetwork Psychology [J]. Journal of China Radio and Television,2020(04):127.

[9] Yang J, Li GY. Research on College Students' Network Psychological Problems and Countermeasures in the Context of "Micro-era" [J]. Science and Education Wenhui (MidJun.),2020(03):155-156.

[10] Yang Y, Li JD. Study on the Effect Expectation and influencing Factors of Micro-course auxiliarymental health course for College Students[J]. Higher Education Forum, 2020(03): 101105 